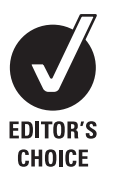

${ }^{1}$ German Rheumatism Research Centre, Epidemiology Unit, Berlin, Germany; ${ }^{2}$ University of Magdeburg, Magdeburg, Germany; ${ }^{3}$ Hildesheim, Germany; ${ }^{4}$ University of Wuerzburg, Wuerzburg, Germany; ${ }^{5}$ Weener, Germany: ${ }^{6}$ Charité University Medicine, Department of Rheumatology, Berlin, Germany

Correspondence to: Dr A Strangfeld, German Rheumatism Research Centre, Epidemiology Unit, Chariteplatz 1, 10117 Berlin, Germany; Strangfeld@drfz.de

Accepted 16 December 2008 Published Online First

5 January 2009

\title{
Comparative effectiveness of tumour necrosis factor $\alpha$ inhibitors in combination with either methotrexate or leflunomide
}

\author{
A Strangfeld, ${ }^{1}$ F Hierse, ${ }^{1} \mathrm{~J}$ Kekow, ${ }^{2} \mathrm{U}$ von Hinueber, ${ }^{3} \mathrm{H}-\mathrm{P}$ Tony, ${ }^{4} \mathrm{R}$ Dockhorn, ${ }^{5}$ \\ J Listing, ${ }^{1}$ A Zink ${ }^{1,6}$
}

\section{ABSTRACT}

Objective: The objective of this study was to compare the effectiveness of a combination of tumour necrosis factor $\alpha$ (TNF $\alpha$ ) inhibitors with either methotrexate or leflunomide in the treatment of patients with rheumatoid arthritis in a real-world setting.

Methods: Data from 1769 outpatients enrolled in the German biologics register RABBIT who were treated with one of the TNF $\alpha$ inhibitors adalimumab, etanercept, or infliximab in combination with either methotrexate ( $n=1375$ ) or leflunomide ( $n=394$ ) were included in the analysis. Clinical status including disease activity as well as treatment data were documented by the treating rheumatologist at baseline and at 3, 6, 12, 18, 24, 30 and 36 months of follow-up.

Results: Patients treated with a combination of biologics with leflunomide had significantly higher baseline disease activity than those treated with methotrexate. The highest disease activity was found for patients treated with the combination infliximab/leflunomide. After 36 months, the discontinuation rates were $46.3 \%, 51.3 \%$ and $61.5 \%$ for combinations of etanercept, adalimumab and infliximab with methotrexate and $53.4 \%, 63.1 \%$ and $67.1 \%$ for combinations with leflunomide, respectively. European League Against Rheumatism response rates after 24 months ranged from $74 \%$ to $81 \%$ for combinations with methotrexate and $72 \%$ to $81 \%$ for combinations with leflunomide.

Conclusion: The current clinical practice is to use methotrexate as a first choice for the combination with TNF $\alpha$ antagonists. In a number of patients methotrexate has to be replaced by another disease-modifying antirheumatic drug. Our data support the view that leflunomide is a useful alternative if methotrexate is contraindicated.

Tumour necrosis factor $\alpha$ (TNF $\alpha$ ) inhibitors and other biological agents targeting $B$ and $T$ cells have undoubtedly been the most important therapeutic innovation in rheumatology in the past decade. These substances are currently routinely used in the clinical management of patients with active rheumatoid arthritis (RA) refractory to traditional disease-modifying antirheumatic drugs (DMARD). Randomised controlled trials have proved not only the efficacy of these substances compared with placebo ${ }^{1-3}$ but also the superiority of a combination therapy with methotrexate over monotherapy with etanercept or adalimumab. ${ }^{4}$ Since the licence for infliximab stipulates use in conjunction with methotrexate, no trials on infliximab monotherapy have been performed in RA. Observational studies have shown longer adherence to anti-TNF $\alpha$ therapy with concomitant methotrexate treatment than to anti-TNF $\alpha$ monotherapy. ${ }^{67}$ The majority of RA patients currently treated with biologics combine this therapy with a traditional DMARD, usually methotrexate. When methotrexate is contraindicated, biologics in combination with other DMARD are increasingly used, despite a lack of specifically designed randomised clinical trials assessing these possible alternative combination therapies. In this situation, real-world data on the effectiveness and safety of treatment combinations arising from carefully conducted observational cohort studies are the second best source of evidence.

One treatment option lacking sufficient supporting data is the combination of anti-TNF $\alpha$ agents with leflunomide. Leflunomide is an immunomodulatory and anti-inflammatory agent that inhibits pyrimidine synthesis. Its efficacy in the treatment of moderate to severe RA has been shown in several randomised trials. ${ }^{8-10}$ In addition, there is conflicting information from smaller observational datasets on the safety and effectiveness of combinations of individual cytokine inhibitors with leflunomide. ${ }^{11-13}$ A large study investigating adalimumab combined with several DMARD showed slightly lower effectiveness for adalimumab/leflunomide compared with adalimumab/methotrexate. ${ }^{14}$ From the Swiss clinical quality management database, quite recent data on all biologicals together in combination with either methotrexate or leflunomide were published, ${ }^{15}$ but no direct comparison of the three individual anti-TNF $\alpha$ agents in combination with methotrexate or leflunomide has been performed.

In the following study, we analysed data from the German biologics register RABBIT, a large prospective cohort study investigating the safety and effectiveness of biological agents in comparison with standard DMARD therapy. The following questions were addressed: (1) What is the drug survival rate of a first treatment with one of the three anti-TNF $\alpha$ agents adalimumab, etanercept and infliximab in combination with either methotrexate or leflunomide over 3 years of observation? (2) How effective is each of the six treatment options?

\section{PATIENTS AND METHODS \\ Patients}

The German biologics register RABBIT is an ongoing, nation-wide prospective cohort study 
Table 1 Patient characteristics

\begin{tabular}{|c|c|c|c|c|c|c|c|}
\hline & ETA + MTX & ETA + LEF & ADA + MTX & ADA + LEF & INF + MTX & INF + LEF & $\begin{array}{l}\text { Biologics/MTX vs } \\
\text { biologics/LEF } \\
\text { p values }\end{array}$ \\
\hline $\mathrm{N}$ & 448 & 144 & 566 & 174 & 361 & 76 & \\
\hline Disease duration in years, median (IOR) & $8(4-15)$ & $8(5-14)$ & $10(5-17)$ & $9(4-16)$ & $8(5-14)$ & $9(5-14)$ & 0.68 \\
\hline$\%$ Female & 75.5 & 69.4 & 78.1 & 78.7 & 71.8 & 77.6 & 0.86 \\
\hline Rheumatoid factor positive (\%) & 78.8 & 82.6 & 80.4 & 79.9 & 79.8 & 73.7 & 0.995 \\
\hline ESR at $\mathrm{t}_{0}, \mathrm{~mm} / \mathrm{h}$, median (IOR) & $29(16-50)$ & $38(20-60)$ & $28(16-44)$ & $30(18-48)$ & $30(15-51)$ & $42(22-67)$ & $<0.0001$ \\
\hline $\mathrm{CRP}, \mathrm{mg} / \mathrm{l}$, median (IQR) & $18(8-36)$ & $20(9-52)$ & $14(6-34)$ & $15(8-33)$ & $21(8-47)$ & $22(12-47)$ & 0.15 \\
\hline DAS28 at $t_{0}$ & $5.7(1.3)$ & $5.8(1.2)$ & $5.5(1.2)$ & $5.7(1.2)$ & $5.8(1.2)$ & $6.1(1.2)$ & 0.027 \\
\hline$\%$ Erosive at $t_{0}$ & 79.9 & 79.0 & 79.1 & 80.3 & 82.6 & 84.7 & 0.86 \\
\hline$\%$ Ever treated with biologics & 15.0 & 9.0 & 26.9 & 20.7 & 16.9 & 9.2 & 0.006 \\
\hline No of previous traditional DMARD & $3.3(1.4)$ & $3.3(1.2)$ & $3.1(1.2)$ & $3.2(1.1)$ & $3.4(1.4)$ & $3.7(1.4)$ & 0.47 \\
\hline
\end{tabular}

Values are means and standard deviations if not otherwise specified. ADA, adalimumab; CRP, C-reactive protein; DAS28, disease activity score based on 28 joint counts; DMARD, disease-modifying antirheumatic drug; ESR, erythrocyte sedimentation rate; ETN, etanercept; FFbH, Hannover functional status questionnaire measuring functional capacity in percentage of full function; HAQ, health assessment questionnaire; INF, infliximab; IOR, interquartile range; LEF, leflunomide; MTX, methotrexate.

that was begun in 2001 with the aim of investigating the safety and effectiveness of new treatment options for RA in routine care. Observation of patients treated with infliximab or etanercept began on 1 May 2001 and patients treated with adalimumab have been enrolled since September 2003. Further details of the study have been published elsewhere. ${ }^{716}$

Patients aged 18-75 years meeting the American College of Rheumatology criteria for RA who were enrolled in RABBIT between 1 May 2001 and 31 December 2006 were included in the following analysis.

We included all patients who had begun treatment with one of the three currently available anti-TNF $\alpha$ agents in combination with either methotrexate or leflunomide ( $\mathrm{n}=1769$ ). Patients receiving anti-TNF $\alpha$ monotherapy $(n=1125)$ were disregarded. As a result of low numbers in the subgroups patients receiving methotrexate plus leflunomide ( $\mathrm{n}=85$ ) as well as those receiving other DMARD alone or in various combinations $(n=285)$ were also excluded from the analysis. From the analysis of disease activity and functional capacity during the first 2 years we excluded a further 728 patients with a follow-up time of less than 24 months, which was mostly due to enrollment after 1 January 2005.

\section{Assessments}

The complete clinical status (including the disease activity score based on 28 joint counts (DAS28), ${ }^{17}$ rheumatoid factor, erosiveness, co-morbidity), treatment history as well as current therapies with biologics and/or conventional DMARD including start and stop dates and reasons for treatment termination were recorded by the treating rheumatologist at baseline and at 3, 6, 12, 18, 24, 30 and 36 months of follow-up. At the same timepoints the patients answered questionnaires pertaining to health status, quality of life and functional disability, measured by the Hannover functional status questionnaire (FFbH), which is comparable with the health assessment questionnaire (HAQ) and can be transformed to $\mathrm{HAQ}$ values using the formula: $\mathrm{HAQ}=3.16-(0.028 \times \mathrm{FFbH}) .^{18}$

\section{Statistics}

Follow-up data of 36 months were used to calculate treatment continuation rates and effectiveness measures of anti-TNF $\alpha$ treatment with methotrexate compared with treatment with leflunomide. Treatment continuation rates were estimated using the Kaplan-Meier method and compared between the six subgroups of patients receiving TNF $\alpha$ inhibitors plus methotrexate or TNF $\alpha$ inhibitors plus leflunomide by log rank test.

An intent-to-treat (ITT) analysis and a completer analysis of patients who continued the initial therapy were performed with DAS28 and FFbH as outcomes. European League against Rheumatism (EULAR) response rates ${ }^{19}$ were calculated in addition.

To compare the effectiveness of the three TNF $\alpha$ inhibitors in combination with either methotrexate or leflunomide, the outcome in the DAS28 at 6, 12, 18 and 24 months was investigated by a nested linear mixed model approach. Using the SAS procedure PROC MIXED, treatments with either methotrexate or leflunomide were compared within the subgroups of patients starting treatment with adalimumab, etanercept, or infliximab, respectively. To take baseline differences among the groups into account, we adjusted for baseline disease activity (DAS28), function (FFbH), percentage of men, previous biologics therapy, year of follow-up and year of study entry. The linear mixed model was used to calculate adjusted least square estimates of the mean DAS28 scores over the timepoints $6,12,18$ and 24 months, as well as their $95 \%$ CI. The following adjustments were made by assuming an equal starting point of the treatment groups at baseline: DAS28 5.7; FFbH 57 (approximate $\mathrm{HAQ} 1.6) ; 75 \%$ women; $20 \%$ treated with biologics at study entry; $50 \%$ study entry before 2004 .

Individual missing DAS28 values were imputed by the estimation-maximation algorithm. ${ }^{20}$ This algorithm uses the individual valid DAS28 scores of a patient to estimate the missing value by taking the correlation of DAS28 scores between different visits into account. By means of this method the missing EULAR response rates (11\%) were replaced.

T-test (DAS28 scores, age), Mann-Whitney test and $\chi^{2}$ tests were applied as appropriate to compare the baseline 

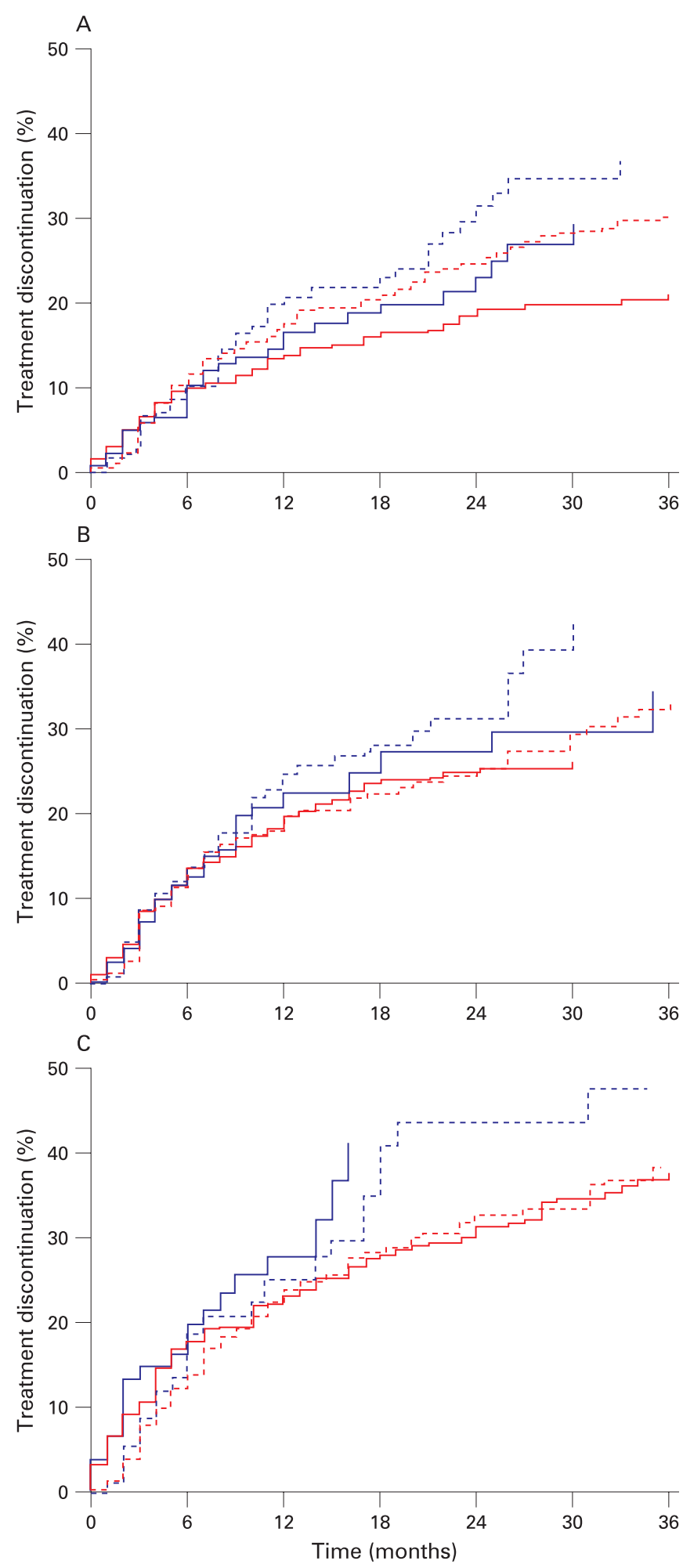

Figure 1 Discontinuation of the initial anti-tumour necrosis factor $\alpha$ therapy: etanercept $(A)$, adalimumab (B) or infliximab (C). Red lines: combination with methotrexate; blue lines: combination with leflunomide; dotted lines: discontinuation as a result of inefficacy; solid lines: discontinuation as a result of adverse events. As many patients had more than one reason for discontinuation, the lines do not sum up to the total discontinuation (see table 2).

characteristics of the patients. Calculations were done by using SAS (version 9.1) software. $\mathrm{p}$ Values less than 0.05 were considered to be statistically significant.

\section{RESULTS}

\section{Baseline characteristics}

At baseline, 740 patients had a new treatment with adalimumab, 592 with etanercept and 437 with infliximab. Of the 1769 total patients, 1375 received a biological agent in combination with methotrexate and 394 patients were treated with a combination of leflunomide. Table 1 shows the baseline characteristics of the patients in the six treatment groups. Patients on a combination of a TNF $\alpha$ inhibitor with leflunomide were slightly older than those on a combination with methotrexate. There were no differences concerning the percentage of women, rheumatoid factor positivity, disability, erosive disease or disease duration. Baseline DAS28 was significantly higher in patients treated with leflunomide compared with those treated with methotrexate as combination partner and ranged from a mean of 5.5 (adalimumab/ methotrexate) to 6.1 (infliximab/leflunomide). The mean number of previous DMARD ranged from 3.1 (adalimumab/ methotrexate) to 3.7 (infliximab/leflunomide). Between 15\% and $27 \%$ of patients receiving a combination of methotrexate and between $9 \%$ and $21 \%$ of those treated with leflunomide had previously been treated with a biological agent. As adalimumab was licensed later than etanercept and infliximab, the percentage of patients with previous failure on a biological agent was highest for this drug. The percentage of patients with co-morbid conditions was high in all groups: between $63 \%$ for adalimu$\mathrm{mab} / \mathrm{methotrexate}$ and $71 \%$ for etanercept/methotrexate. The median number of chronic co-morbidities was four for infliximab/leflunomide and three for all other groups. The median follow-up time ranged from 20 to 36 months and was lower for adalimumab than for the other TNF $\alpha$ inhibitors.

\section{Discontinuation of a first anti-TNF $\alpha$ treatment in combination with methotrexate or leflunomide}

Figure 1 shows the discontinuation rates over the first 36 months for etanercept, adalimumab and infliximab in combination with either methotrexate or leflunomide. The rates for discontinuation as a result of adverse events and inefficacy are displayed separately. They do not sum up to the total discontinuation because in a considerable proportion of cases both reasons applied. Within the first 6-12 months the curves are almost indistinguishable, whereas in the second and third years the combinations with leflunomide have slightly higher discontinuation rates than those with methotrexate. This difference is, however, not statistically significant. After 36 months, treatment termination as a result of inefficacy occurred more frequently than as a result of adverse events in all groups.

Table 2 displays the total percentages of discontinuation after 12, 24 and 36 months. Stops due to remission or noncompliance that occurred in $2.8 \%$ of the patients are not included.

\section{Discontinuation of the concomitant DMARD}

In most of the cases, the patients were already on the respective DMARD when the TNF $\alpha$ inhibitor was started. This applied to $75.3 \%$ of patients treated with methotrexate and $88.6 \%$ of those treated with leflunomide. If we total all three anti-TNF $\alpha$ agents and analyse the treatment continuation of the concomitant DMARD before the termination of the anti-TNF $\alpha$ agent, methotrexate was terminated in $8.7 \%$ after 12 months and $17.0 \%$ (95\% CI $14.2 \%$ to $20.4 \%$ ) after 36 months, whereas termination of leflunomide occurred in $26.1 \%$ after 12 months 
Table 2 Percentage of patients who stopped the initial anti-TNF $\alpha$ therapy after 12, 24 and 36 months

\begin{tabular}{|c|c|c|c|c|c|}
\hline & \multirow[b]{2}{*}{$\mathrm{n}$} & \multirow{2}{*}{$\begin{array}{l}\text { p Value* } \\
\text { MTX vs LEF }\end{array}$} & \multicolumn{3}{|c|}{ Months } \\
\hline & & & 12 & 24 & 36 \\
\hline $\mathrm{ETA}+\mathrm{MTX}$ & 448 & & 29.6 & 40.8 & 46.3 \\
\hline $\mathrm{ETA}+\mathrm{LEF}$ & 144 & 0.73 & 32.9 & 46.3 & 53.4 \\
\hline$A D A+M T X$ & 566 & & 35.1 & 44.3 & 51.3 \\
\hline$A D A+L E F$ & 174 & 0.074 & 42.5 & 51.5 & 63.1 \\
\hline INF + MTX & 361 & & 41.1 & 54.2 & 61.5 \\
\hline INF + LEF & 76 & 0.31 & 45.7 & 64.6 & 67.1 \\
\hline
\end{tabular}

${ }^{*}$ Comparison of anti-tumour necrosis factor (TNF) agent plus methotrexate (MTX) with anti-TNF agent plus leflunomide (LEF) over 36 months by log rank test. ADA, adalimumab; ETA, etanercept; INF, infliximab.

and $36.6 \%$ (95\% CI $29.1 \%$ to $45.4 \%$ ) after 36 months. The difference between methotrexate and leflunomide was highly significant $(p<0.001)$. The majority of patients remained on anti-TNF monotherapy; a new treatment start with a DMARD as combination partner of the ongoing anti-TNF therapy was observed during the next 12 months in only $20 \%$ of the patients who stopped their previous DMARD.

If patients were switched to another biological agent, $80 \%$ of patients with the combination of a TNF $\alpha$ inhibitor with methotrexate and $72 \%$ of those who had leflunomide as concomitant therapy at study entry remained on the initial DMARD.

\section{Effectiveness of anti-TNF $\alpha$ treatment with methotrexate or leflunomide}

Table 3 shows the unadjusted and adjusted mean DAS28 scores averaged over months 6,12, 18 and 24 in completers of the initial biological therapy and in the ITT population. As the baseline values of the six groups were not equal (see table 1 ) and the outcome of the DAS28 depends on the baseline status, an equal baseline status was assumed for all subgroups to calculate the adjusted means (see Methods section for further details). This led, however, to only minor differences compared with the unadjusted outcome. For completers, the effectiveness was significantly higher than for non-completers (data not shown) $(p<0.001)$. For completers, the adjusted mean DAS28 decreased from the uniform starting point of 5.7 to 3.3 for etanercept/ methotrexate, 3.4 for adalimumab/methotrexate, 3.5 for inflix$\mathrm{imab} / \mathrm{methotrexate,} \mathrm{etanercept/leflunomide} \mathrm{as} \mathrm{well} \mathrm{as} \mathrm{for}$ adalimumab/leflunomide and 4.0 for the small group of infliximab/leflunomide. The outcome did not differ significantly between patients initially treated with adalimumab, etanercept or infliximab, respectively $(p=0.15)$. When we compared combinations with methotrexate with combinations with leflunomide within each anti-TNF group the differences between methotrexate and leflunomide were not statistically significant (completer analysis $\mathrm{p}=0.15$; ITT population $\mathrm{p}=0.08)$.

Crude rates of EULAR response after 24 months are shown in fig 2. A good EULAR response was achieved by 347/1040 (33\%; $95 \%$ CI $31 \%$ to $36 \%$ ) of patients of the ITT population and by $235 / 557$ (42\%; $95 \%$ CI $38 \%$ to $46 \%$ ) of the completers. Lower rates of good response were observed in the infliximab/ leflunomide subgroup. This difference did, however, not achieve statistical significance and was partly due to a higher number of DMARD failures and higher DAS28 baseline values in this subgroup.

Functional capacity improved by $8.5 \%$ on the $0-100 \% \mathrm{FFbH}$ scale in the ITT population (combinations with methotrexate $8.9 \%$; with leflunomide $7.1 \%$ ) and by $11.7 \%$ in completers (combinations with methotrexate 11.9\%; with leflunomide $10.7 \%)$. The changes in the ITT and in the completer populations correspond to changes in $\mathrm{HAQ}$ values of 0.24 and 0.33 , respectively. There were no significant differences between the six groups (table 4).

\section{DISCUSSION}

In this study, $18.4 \%$ of the patients treated with a combination of anti-TNF $\alpha$ agents and DMARD received leflunomide as the concomitant DMARD. This is comparable with the results reported by Finckh et a ${ }^{15}$ from Switzerland, in which $21 \%$ of the patients received a combination of anti-TNF $\alpha$ and leflunomide. In that Swiss study, 842 patients received anti-TNF $\alpha$ plus methotrexate and 260 patients anti-TNF $\alpha$ plus leflunomide. Although the mean age and disease duration were comparable between the two studies, the baseline DAS28 was significantly higher in our data (5.5-6.1) compared with the Swiss data (4.14.6). Functional disability was higher in our patients (HAO 1.51.6 compared with $1.2-1.3$ in the Swiss data). Another difference between our study and the Swiss study is that, in

Table 3 Mean DAS28 after 6-24 months for completers of the initial biological therapy and for all patients (ITT analysis)

\begin{tabular}{|c|c|c|c|c|c|c|}
\hline & \multicolumn{3}{|c|}{ Completers only } & \multicolumn{3}{|c|}{ All patients } \\
\hline & \multirow[b]{2}{*}{$\mathbf{n}$} & \multirow{2}{*}{$\begin{array}{l}\text { Mean of DAS28 at } 6 \text {, } \\
12,18 \text { and } 24 \text { months } \\
(95 \% \mathrm{CI}) \\
\text { Unadjusted }\end{array}$} & \multirow{2}{*}{$\begin{array}{l}\text { Mean of DAS28 at } 6, \\
12,18 \text { and } 24 \text { months } \\
(95 \% \mathrm{CI}) \\
\text { Adjusted* }\end{array}$} & \multirow[b]{2}{*}{$\mathbf{n}$} & \multirow{2}{*}{$\begin{array}{l}\text { Mean of DAS28 at } 6 \text {, } \\
12,18 \text { and } 24 \text { months } \\
\text { (95\% CI) } \\
\text { Unadjusted }\end{array}$} & \multirow{2}{*}{$\begin{array}{l}\text { Mean of DAS28 at 6, } \\
12,18 \text { and } 24 \text { months } \\
(95 \% \mathrm{CI}) \\
\text { Adjusted* }\end{array}$} \\
\hline & & & & & & \\
\hline ETA/MTX & 182 & 3.3 (3.2 to 3.5$)$ & 3.3 (3.2 to 3.5$)$ & 305 & 3.8 (3.7 to 4.0$)$ & 3.8 (3.7 to 3.9 ) \\
\hline ETA/LEF & 49 & 3.4 (3.1 to 3.7$)$ & 3.5 (3.2 to 3.7$)$ & 78 & 3.9 (3.6 to 4.2$)$ & 3.8 (3.6 to 4.1$)$ \\
\hline ADA/MTX & 156 & 3.4 (3.2 to 3.6$)$ & 3.4 (3.3 to 3.6$)$ & 274 & 3.8 (3.6 to 3.9 ) & 3.8 (3.6 to 3.9$)$ \\
\hline ADA/LEF & 40 & 3.5 (3.2 to 3.8$)$ & 3.5 (3.2 to 3.8$)$ & 80 & 3.9 (3.6 to 4.2$)$ & 3.9 (3.7 to 4.2$)$ \\
\hline INF/MTX & 112 & 3.4 (3.4 to 3.8$)$ & 3.5 (3.3 to 3.7$)$ & 250 & 4.0 (3.8 to 4.2$)$ & $3.8(3.7$ to 4.0$)$ \\
\hline INF/LEF & 19 & 4.2 (3.7 to 4.7$)$ & $4.0(3.6$ to 4.4$)$ & 54 & $4.4(4.0$ to 4.7$)$ & 4.2 (3.9 to 4.5$)$ \\
\hline
\end{tabular}

${ }^{*}$ Means adjusted for disease activity score based on 28 joint counts (DAS28) at baseline, function, percentage of men, previous biological therapy, year of follow-up, year of study entry; see Statistics section. ADA, adalimumab; ETA, etanercept; INF, infliximab; ITT, intent-to-treat; LEF, leflunomide; MTX, methotrexate. 
Figure 2 Crude rates of European League Against Rheumatism response at 24 months in percentages. ADA, adalimumab; ETA, etanercept; INF, infliximab; LEF, leflunomide; MTX, methotrexate.

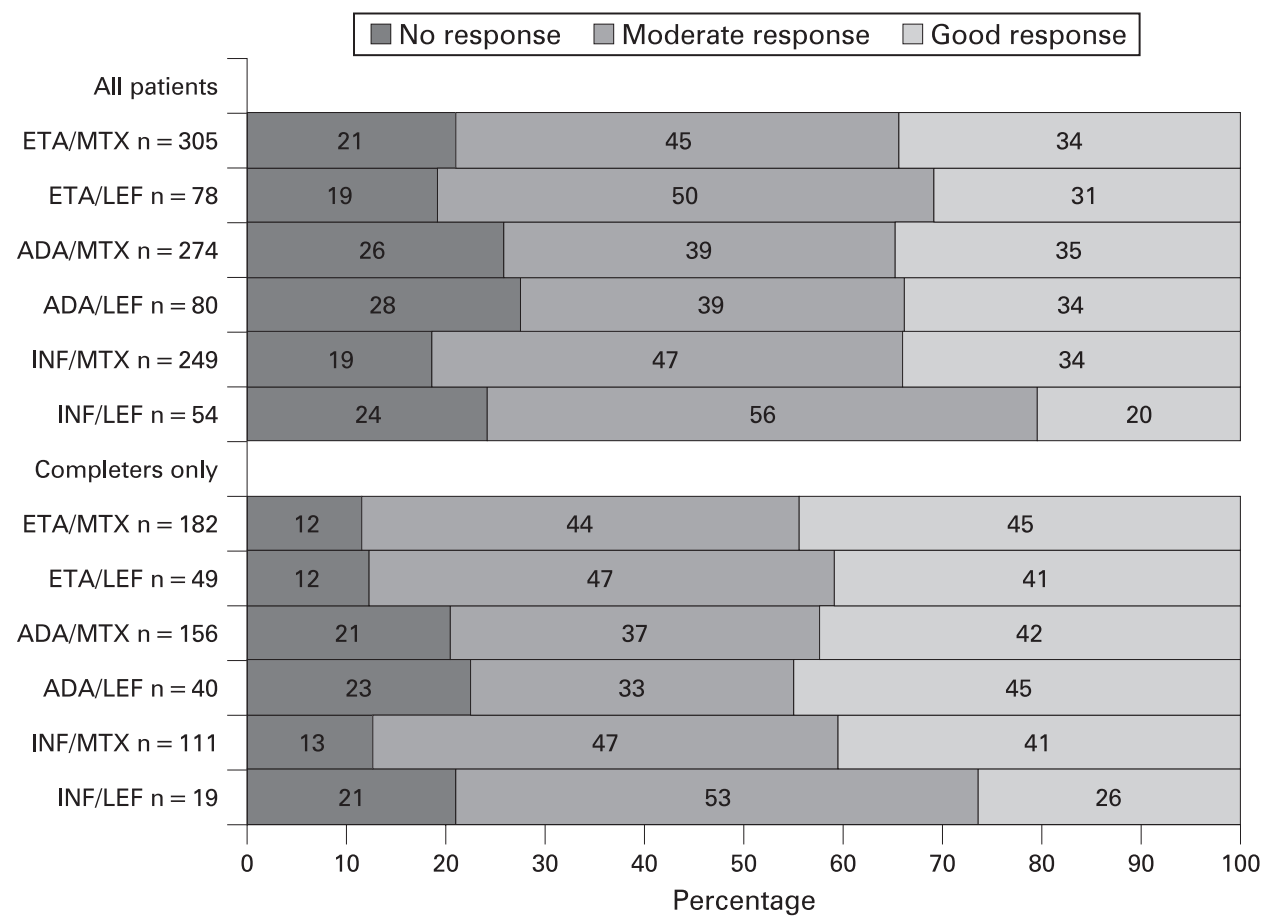

the Swiss dataset, more than one-third of the patients had already failed at least one anti-TNF $\alpha$ treatment, whereas this was the case for only $19 \%$ of our patients.

The survival rates after one year for a first biological therapy in combination with methotrexate of approximately $70 \%$ for etanercept and 59\% for infliximab are in agreement with our previous report. ${ }^{7}$ Drug survival of adalimumab, which was not reported by us earlier, was $65 \%$ after one year in combination with methotrexate. After 3 years, the survival rates ranged from $54 \%$ to $39 \%$ in combination with methotrexate and from $47 \%$ to $33 \%$ in combination with leflunomide. The British biologics register reported survival rates of $71 \%$ for etanercept, $70 \%$ for adalimumab and 58\% for infliximab after 12, 10, and 16 months of follow-up, respectively. ${ }^{21}$ The South Swedish Register reported higher adherence to therapy at one and 2 years with etanercept/methotrexate (90\% and $87 \%$, respectively) compared with infliximab/methotrexate (68\% and $60 \%$, respectively). ${ }^{6}$

We found considerably higher DAS28 treatment responses than the Swiss study. Finckh et al ${ }^{15}$ reported a mean DAS28 improvement of 0.74 for the combination of anti-TNF $\alpha$ agents with methotrexate and 0.63 for the combination with leflunomide after one year, whereas in our data the mean improvement over the timepoints 6, 12, 18 and 24 months was 1.7-1.9 in the different treatment groups. Twenty to $34 \%$ of our patients achieved a good and $45-56 \%$ a moderate EULAR response compared with $19 \%$ and $45 \%$ in the Swiss study. Seventy-two to $81 \%$ of our patients were thus responders after 2 years compared with $64 \%$ in the Swiss study after one year. Flendrie and colleagues ${ }^{22}$ found $76 \%$ EULAR responders after 24 months for the combination of infliximab with leflunomide, which is identical to our data. The Finnish register ROB-FIN ${ }^{23}$ analysed 364 RA patients on different DMARD combinations with infliximab and found no difference in effectiveness between the various combinations.

The strength of our analysis is that it is based upon real-world data from a large prospective cohort study, observing different treatment regimes. This allows for head-to-head comparisons between different biological agents and different concomitant

Table 4 Mean FFbH after 6-24 months for completers of the initial biological therapy and for all patients (ITT analysis)

\begin{tabular}{|c|c|c|c|c|c|c|}
\hline & \multicolumn{3}{|c|}{ Completers only } & \multicolumn{3}{|c|}{ All patients } \\
\hline & \multirow[b]{2}{*}{$\mathbf{n}$} & \multirow{2}{*}{$\begin{array}{l}\text { Mean of FFbH at } 6 \text {, } \\
12,18,24 \text { months } \\
(95 \% \mathrm{CI}) \\
\text { Unadjusted }\end{array}$} & \multirow{2}{*}{$\begin{array}{l}\text { Mean of FFbH at } 6 \text {, } \\
12,18,24 \text { months } \\
(95 \% \mathrm{CI}) \\
\text { Adjusted* }^{*}\end{array}$} & \multirow[b]{2}{*}{$\mathbf{n}$} & \multirow{2}{*}{$\begin{array}{l}\text { Mean of FFbH at } 6 \text {, } \\
12,18,24 \text { months } \\
\text { (95\% CI) } \\
\text { Unadjusted }\end{array}$} & \multirow{2}{*}{$\begin{array}{l}\text { Mean of FFbH at } 6 \\
12,18,24 \text { months } \\
(95 \% \mathrm{CI}) \\
\text { Adjusted* }\end{array}$} \\
\hline & & & & & & \\
\hline ETA/MTX & 182 & $69.9(66.9$ to 73.0$)$ & $68.2(66.1$ to 70.2$)$ & 305 & $65.9(63.4$ to 68.4$)$ & $65.2(63.6$ to 66.7$)$ \\
\hline ETA/LEF & 49 & 71.7 (65.7 to 77.6$)$ & 69.2 (65.2 to 73.1$)$ & 78 & $66.0(61.1$ to 71.0$)$ & $65.6(62.4$ to 68.7$)$ \\
\hline ADA/MTX & 156 & 69.8 (66.5 to 73.1$)$ & 67.6 (65.2 to 69.9 ) & 274 & $66.0(63.4$ to 68.7$)$ & $65.1(63.3$ to 66.9$)$ \\
\hline ADA/LEF & 40 & $67.9(61.4$ to 74.5$)$ & 67.0 (62.5 to 71.4$)$ & 80 & $62.9(58.0$ to 67.8$)$ & 63.0 (59.9 to 66.2$)$ \\
\hline INF/MTX & 112 & 70.8 (66.8 to 74.7$)$ & 71.2 (68.5 to 73.8 ) & 250 & 65.3 (62.6 to 68.1$)$ & $66.8(65.0$ to 68.6$)$ \\
\hline INF/LEF & 19 & 69.2 (59.7 to 78.8 ) & 66.5 (60.2 to 72.7$)$ & 54 & 67.4 (61.4 to 73.3$)$ & $64.2(60.3$ to 68.0$)$ \\
\hline MTX total & & & 68.9 (67.6 to 70.2$)$ & & & $65.9(64.9$ to 66.8$)$ \\
\hline LEF total & & & 67.7 (64.9 to 70.6$)$ & & & 64.1 (62.1 to 66.0$)$ \\
\hline
\end{tabular}

\footnotetext{
${ }^{*}$ Means adjusted for disease activity score based on 28 joint counts (DAS28) at baseline, function, percentage of men, previous biological therapy, year of follow-up, year of study entry; see Statistics section.
}

ADA, adalimumab; ETA, etanercept; FFbH, Hannover functional status questionnaire; INF, infliximab; ITT, intent-to-treat; LEF, leflunomide; MTX, methotrexate. 
DMARD. The study design, however, is also responsible for a general limitation: in real practice treatments are given according to the need of the patient, leading to confounding by indication in observational studies. As methotrexate is the first-line DMARD in Germany, leflunomide is usually given after the failure of methotrexate, and patients with experience of failure tend to be sicker than those who remain on their first therapy. We tried to overcome this problem by adjusting the changes in response parameters for differences in baseline values; however, we cannot rule out residual confounding.

Some earlier reports have shown high rates of adverse events in the combination of infliximab with leflunomide. In 17 out of 40 patients in a study by Bingham et al, ${ }^{12}$ the treatment had to be withdrawn as a result of adverse events. In the study by Kiely and Johnson, ${ }^{11} 11$ out of 20 patients stopped treatment before 34 weeks. Later reports with larger numbers of patients did not confirm this high adverse event rate and showed that drug survival was better if infliximab was introduced later than leflunomide. ${ }^{13}$ Flendrie et $a l^{22}$ observed in patients with previous or concomitant leflunomide therapy a similar safety profile of infliximab compared with other combinations or infliximab monotherapy. In a recent open-label clinical trial ${ }^{24}$ infliximab was given in addition to an ongoing treatment with leflunomide. Twelve out of 70 patients $(17 \%)$ withdrew as a result of adverse events within 30 weeks, which is similar to our results.

\section{CONCLUSION}

We know from several randomised clinical studies that anti$\mathrm{TNF} \alpha$ agents are more efficient in combination with methotrexate than given as monotherapy. In daily practice, rheumatologists therefore frequently use this combination, even when prescribing biological agents that are also licensed as monotherapy. As anti-TNF $\alpha$ agents are usually given after the failure of two or more traditional DMARD, patients are often switched to an anti-TNF $\alpha$ treatment after having failed on methotrexate and after having tried leflunomide as the second DMARD. If leflunomide is well tolerated but insufficiently effective, adding the biological agent is the usual choice. Our data confirm that in real life the effectiveness of a combination of a TNF $\alpha$-blocking agent with leflunomide is only slightly lower than a combination with methotrexate. Taking into account that patients treated with leflunomide have usually previously failed on methotrexate and have therefore a higher a-priori chance of further failure, our data support the current practice of using leflunomide as a second DMARD after methotrexate in the combination with anti-TNF $\alpha$ treatments.

Acknowledgements: The authors acknowledge the invaluable contributions of all participating consultant rheumatologists and would like to thank in particular those who enrolled at least 25 patients each: Winfried Demary, MD, Hildesheim; Andreas Krause, MD, Professor of Rheumatology, Immanuel Diakonie Group, Berlin; Maria Stoyanova-Scholz, MD, Wedau Kliniken, Duisburg; Karin Babinsky, MD, Halle; Thilo Klopsch, MD, Neubrandenburg; Constanze Richter, MD, Stuttgart; Gerd-Rüdiger Burmester, MD, Professor of Rheumatology, Charité University School of Medicine, Berlin; Karin Rockwitz, Goslar; Arnold Bussmann, MD, Geilenkirchen; Katja Richter, MD, Universitätsklinikum Carl Gustav Carus, Dresden; Brigitte Krummel-Lorenz, MD, Frankfurt/Main; Anett Grässler, MD, Pirna; Elke Wilden, MD, Köln; Michael Hammer MD, Professor of Rheumatology, St Josef-Stift, Sendenhorst; Edmund Edelmann, MD, Bad Aibling; Christina Eisterhues, MD, Braunschweig; Wolfgang Ochs, MD, Bayreuth; Thomas Karger, MD, Eduardus-Krankenhaus, Köln-Deutz; Michael Bäuerle, MD, Universität Erlangen, Erlangen; Herbert Kellner, MD, Professor of Rheumatology, München; Silke Zinke, MD, Berlin; Angela Gause, MD, Professor of Rheumatology, Elmshorn; Lothar Meier, MD, Hofheim; Karl Alliger, MD, Zwiesel; Martin Bohl-Bühler, Brandenburg; Carsten Stille, MD, Hannover; Susanna Späthling-Mestekemper, MD, and Thomas Dexel, MD, München; Peter Herzer, MD, Professor of Rheumatology, München, Harald Tremel, MD, Hamburg; Stefan Schewe, MD, Professor of Rheumatology, Medizinische Poliklinik der Ludwig-Maximilians-Universität, München;
Helmut Sörensen, MD, Krankenhaus Waldfriede, Berlin; Florian Schuch, MD, Erlangen; Klaus Krüger, MD, Professor of Rheumatology, München; Andreas Teipel, MD, Leverkusen; Kirsten Karberg, MD, Berlin; Gisela Maerker-Alzer, MD, Professor of Rheumatology and Dorothea Pick, MD, Holzweiler; Volker Petersen, MD, Hamburg; Kerstin Weiss, MD, Lichtenstein; Werner Liman, MD, Ev Krankenhaus, Hagen-Haspe; Kurt Gräfenstein, MD, Professor of Rheumatology, Johanniter-Krankenhaus im Fläming, Treuenbrietzen; Jochen Walter, MD, Rendsburg; Werner A Biewer, MD, Saarbrücken; Roland Haux, MD, Berlin; Gross, MD, Lübeck; Michael Zänker, MD, Evangelisches Freikirchliches Krankenhaus, Eberswalde; Gerhard Fliedner, MD, Osnabrück; Thomas Grebe, MD, Ev Krankenhaus, Kredenbach; Karin Leumann, MD, Riesa; Jörg-Andres Rump, MD, Freiburg; Joachim Gutfleisch, MD, Biberbach; Michael Schwarz-Eywill, MD, Evangelisches Krankenhaus, Oldenburg; Kathrin Fischer, MD, Greifswald; Monika Antons, MD, Köln. The authors also acknowledge the significant contribution to the conception of RABBIT of Rolf Rau, MD, Professor of Rheumatology, Matthias

Schneider, MD, Professor of Rheumatology, Duesseldorf, and Peter Herzer, MD, Rheumatologist, Muenchen, in their function as members of the advisory board. The substantial contribution of Christina Bungartz, Ulrike Kamenz and Susanna Zernicke in study monitoring and support of the data analyses is gratefully recognised.

Funding: RABBIT has been supported by an unconditional, joint grant from Essex Pharma (since 2001), Wyeth Pharma (since 2001), Amgen (since 1/2003), Abbott (since 9/2003), Roche Pharma (since 1/2007) and Bristol-Myers Squibb (since 7/ 2007).

\section{Competing interests: None.}

Ethics approval: Ethics approval was obtained from the Ethics Committee of the Charite Medical School, Berlin.

\section{Patient consent: Obtained.}

Role of the sponsors: All six sponsoring companies received the manuscript 30 days before submission for the purposes of information. Under the terms of the RABBIT contract the investigators are free to publish all findings; in case the companies do not agree they can comment on this in a footnote. They do not have any influence on the design and conduct of the study, data collection, development of the analysis plan, or preparation and conducting the analysis. The interpretation of the data, and the drafting, critical revision and approval of the final manuscript was done solely by the authors.

\section{REFERENCES}

1. Keystone EC, Kavanaugh AF, Sharp JT, et al. Radiographic, clinical, and functional outcomes of treatment with adalimumab (a human anti-tumor necrosis factor monoclonal antibody) in patients with active rheumatoid arthritis receiving concomitant methotrexate therapy-a randomized, placebo-controlled, 52-week trial. Arthritis Rheum 2004;50:1400-11.

2. Weinblatt ME, Kremer JM, Bankhurst $A D$, et al. A trial of etanercept, a recombinant tumor necrosis factor receptor:Fc fusion protein, in patients with rheumatoid arthritis receiving methotrexate. N Engl J Med 1999;340:253-9.

3. Maini R, St Clair EW, Breedveld F, et al. Infliximab (chimeric anti-tumour necrosis factor $\alpha$ monoclonal antibody) versus placebo in rheumatoid arthritis patients receiving concomitant methotrexate: a randomised phase III trial. ATTRACT Study Group. Lancet 1999;354:1932-9.

4. Klareskog L, van der Heijde D, de Jager JP, et al. Therapeutic effect of the combination of etanercept and methotrexate compared with each treatment alone in patients with rheumatoid arthritis: double-blind randomised controlled trial. Lancet 2004;363:675-81

5. Breedveld FC, Weisman MH, Kavanaugh AF, et al. The PREMIER study: a multicenter, randomized, double-blind clinical trial of combination therapy with adalimumab plus methotrexate versus methotrexate alone or adalimumab alone in patients with early, aggressive rheumatoid arthritis who had not had previous methotrexate treatment. Arthritis Rheum 2006;54:26-37.

6. Kristensen LE, Saxne T, Nilsson JA, et al. Impact of concomitant DMARD therapy on adherence to treatment with etanercept and infliximab in rheumatoid arthritis. Results from a six-year observational study in southern Sweden. Arthritis Res Ther 2006;8:R174.

7. Zink A, Listing J, Kary S, et al. Treatment continuation in patients receiving biological agents or conventional DMARD therapy. Ann Rheum Dis 2005;64:1274-9.

8. Cohen S, Cannon GW, Schiff M, et al. Two-year, blinded, randomized, controlled trial of treatment of active rheumatoid arthritis with leflunomide compared with methotrexate. Utilisation of Leflunomide in the Treatment of Rheumatoid Arthritis Trial Investigator Group. Arthritis Rheum 2001;44:1984-92.

9. Strand V, Cohen S, Schiff M, et al. Treatment of active rheumatoid arthritis with leflunomide compared with placebo and methotrexate. Leflunomide Rheumatoid Arthritis Investigators Group. Arch Intern Med 1999;159:2542-50.

10. Smolen JS, Kalden JR, Scott DL, et al. Efficacy and safety of leflunomide compared with placebo and sulphasalazine in active rheumatoid arthritis: a double-blind, randomised, multicentre trial. European Leflunomide Study Group. Lancet 1999;353:259-66.

11. Kiely PD, Johnson DM. Infliximab and leflunomide combination therapy in rheumatoid arthritis: an open-label study. Rheumatology (Oxford) 2002;41:631-7.

12. Bingham SJ, Buch $\mathrm{MH}$, Kerr MA, et al. Induction of antinuclear antibodies in patients with rheumatoid arthritis treated with infliximab and leflunomide. Arthritis Rheum 2004;50:4072-3. 
13. Hansen KE, Cush J, Singhal A, et al. The safety and efficacy of leflunomide in combination with infliximab in rheumatoid arthritis. Arthritis Rheum 2004;51:228-32

14. Burmester GR, Mariette X Montecucco C et al. Adalimumab alone and in combination with disease-modifying antirheumatic drugs for the treatment of rheumatoid arthritis in clinical practice: the Research in Active Rheumatoid Arthritis (ReAct) trial. Ann Rheum Dis 2007;66:732-9.

15. Finckh A, Dehler S, Gabay C, on behalf of the SCOM doctors. The effectiveness of leflunomide as co-therapy of tumour necrosis factor inhibitors in rheumatoid arthritis: a population-based study. Ann Rheum Dis 2009;68:33-9.

16. Listing J, Strangfeld A, Kary S, et al. Infections in patients with rheumatoid arthritis treated with biologic agents. Arthritis Rheum 2005;52:3403-12.

17. Prevoo ML, van't Hof MA, Kuper HH, et al. Modified disease activity scores that include twenty-eight-joint counts. Development and validation in a prospective longitudinal study of patients with rheumatoid arthritis. Arthritis Rheum 1995:38:44-8.

18. Lautenschlaeger J, Mau W, Kohlmann T, et al. [Comparative evaluation of a German version of the health assessment questionnaire and the Hannover functional capacity questionnaire]. Z Rheumatol 1997:56:144-55.
19. van Gestel AM, Prevoo MLL, van't Hof MA, et al. Development and validation of European League against Rheumatism response criteria for rheumatoid arthritis. Arthritis Rheum 1996;39:34-40.

20. Dempster AP, Laird NM, Rubin DB. Maximum likelihood from incomplete data via EM algorithm. J Roy Stat Soc Series B-Methodological 1977;39:1-38.

21. Hyrich KL, Lunt $M$, Watson $K D$, et al. Outcomes after switching from one anti-tumor necrosis factor $\alpha$ agent to a second anti-tumor necrosis factor $\alpha$ agent in patients with rheumatoid arthritis: results from a large UK national cohort study. Arthritis Rheum 2007; 56:13-20.

22. Flendrie $\mathbf{M}$, Creemers $\mathrm{MC}$, Welsing $\mathrm{PM}$, et al. The influence of previous and concomitant leflunomide on the efficacy and safety of infliximab therapy in patients with rheumatoid arthritis; a longitudinal observational study. Rheumatology (Oxford) 2005:44:472-8.

23. Nordstrom DC, Konttinen L, Korpela M, et al. Classic disease modifying antirheumatic drugs (DMARDs) in combination with infliximab. The Finnish experience. Rheumatol Int 2006:26:741-8.

24. Kalden JR, Nusslein HG, Wollenhaupt J, et al. Combination treatment with infliximab and leflunomide in patients with active rheumatoid arthritis: safety and efficacy in an open-label clinical trial. Clin Exp Rheumatol 2008;26:834-40.

\section{Submit an eLetter, and join the debate}

eLetters are a fast and convenient way to register your opinion on topical and contentious medical issues. You can find the "submit a response" link alongside the abstract, full text and PDF versions of all our articles. We aim to publish swiftly, and your comments will be emailed directly to the author of the original article to allow them to respond. eLetters are a great way of participating in important clinical debates, so make sure your voice is heard. 